\title{
PERBEDAAN KADAR TRIGLISERIDA WANITA SEBELUM DAN SESUDAH TERAPI BEKAM
}

\author{
Diana Fransiska Sinaga, Putri Widelia Welkriana, Jon Farizal \\ Politeknik Kesehatan Kementerian Kesehatan Bengkulu, Prodi D III Analis Kesehatan \\ Jalan Indragiri Nomor 03 Padang Harapan Kota Bengkulu 38225 \\ dianafransiskasinagal4@gmail.com
}

\begin{abstract}
Wet cupping therapy can excavate the hydrophilic and hydrophobic material one example is lipoprotein. Triglycerides are used as blood biochemical parameters to determine the interference of fat metabolism. Hypertriglyceridemia is a condition that occurs because of increased triglyceride levels that trigger the accumulation of lipids in the walls of the arteries that can cause atherosclerosis. This research is to know the difference of triglyceride level of women before and after cupping therapy at Cottage Alternative Medicine Miftahussyifa Bengkulu City. The research conducted is Analytical. The research design used was researched design pre-experimental with one group pre-post test. The sample in this study were 32 respondents by using purposive sampling method. Samples were measured by method clinical analyzer using a clinical analyzer instrument (Architect Plus C4000®) and using triglyceride reagent (proliferation Abbot). This study showed that of 32 female respondents who had first followed bruise therapy then examined triglyceride levels before and after cupping therapy with the first venous blood taking done before the cordoning, the second venous blood taking was done immediately after the curing of the same sample. The result showed that the mean of triglyceride level before and after cupping therapy decreased with the mean value of triglyceride level before cupping therapy $208,28 \mathrm{mg} / \mathrm{dL}$ and mean value of triglyceride level after cupping therapy $200,59 \mathrm{mg} / \mathrm{dL}$. The result of Ttest analysis is dependent with value $\mathrm{p}=0,002(\mathrm{p}<0,05)$. There are significant differences in triglyceride levels before and after cupping therapy at Cottage Alternative Medicine Miftahussyifa Bengkulu City.
\end{abstract}

Keywords: Cupping Therapy, Triglycerides, Cholesterol.

Abstrak: Terapi bekam basah dapat mengekskresikan material hidrofilik dan hidrofobik salah satu contohnya adalah lipoprotein. Trigliserida digunakan sebagai parameter biokimia darah untuk menentukan gangguan metabolisme lemak. Hipertrigliseridemia merupakan kondisi yang terjadi karena meningkatnya kadar trigliserida yang memicu akumulasi lipid di dinding pembuluh arteri yang dapat menyebabkan terjadinya aterosklerosis. Penelitian ini bertujuan untuk mengetahui perbedaan kadar trigliserida wanita sebelum dan sesudah terapi bekam di Pondok Pengobatan Alternatif Miftahussyifa Kota Bengkulu. Penelitian yang dilakukan bersifat Analitik. Desain penelitian yang digunakan adalah Rancangan penelitian pre-eksperimen dengan one group pre-post test. Sampel pada penelitian ini sebanyak 32 responden dengan menggunakan metode purposive sampling. Sampel diukur dengan metode clinical analyzer menggunakan alat clinical analyzer (Architect Plus $\mathrm{C} 4000 \AA$ ) dan menggunakan reagen pemeriksaan trigliserida (Abbot Architect Plus $\mathrm{C} 4000 \AA)$. Penelitian ini menunjukan bahwa dari 32 responden wanita yang baru pertama kali mengikuti terapi bekam kemudian dilakukan pemeriksaan kadar trigliserida sebelum dan sesudah terapi bekam dengan pengambilan darah vena pertama dilakukan sebelum pembekaman, pengambilan darah vena kedua dilakukan langsung setelah pembekaman pada sampel yang sama. Hasil penelitian didapatkan nilai rerata kadar trigliserida sebelum dan 
sesudah terapi bekam mengalami penurunan dengan nilai rerata kadar trigliserida sebelum terapi bekam $208,28 \mathrm{mg} / \mathrm{dL}$ dan nilai rerata kadar trigliserida sesudah terapi bekam 200,59 $\mathrm{mg} / \mathrm{dL}$. Hasil analisis Uji T dependen dengan nilai $p=0,002$ $(\mathrm{p}<0,05)$. Ada perbedaan kadar trigliserida yang signifikan sebelum dan sesudah terapi bekam di Pondok Pengobatan Alternatif Miftahussyifa Kota Bengkulu Tahun 2018.

Kata Kunci: Terapi bekam, Trigliserida, Kolesterol.

Trigliserida digunakan sebagai parameter gejala penyakit diabetes komplikasi, biokimia darah untuk menentukan sindrom metabolik yang merupakan gangguan metabolisme lemak. gangguan dari beberapa penyakit Hipertrigliseridemia merupakan kondisi komplikasi sebelumnya seperti jantung, yang terjadi karena meningkatnya kadar diabetes melitus, kegemukan dan trigliserida yang memicu akumulasi lipid hipertensi(Oway, Kalangi, \& Pasiak, di dinding pembuluh arteri yang dapat menyebabkan terjadinya aterosklerosis 2013). Menurunkan kadar trigliserida (Patonah, Yuniarto, \& Nurhandayati, 2014).

Trigliserida menyediakan energi bagi proses metabolik tubuh. Trigliserida memiliki fungsi yang hampir sama sangat penting, terutama untuk mencegah penyakit-penyakit berbahaya yang dapat timbul akibat peningkatan kadar trigliserida. Kadar trigliserida di dalam darah dapat diturunkan dengan terapi tradisional bekam. Berdasarkan hasil dengan fungsi karbohidrat (Wowor, Ticoalu, \& Wongkar, 2013). Kadar penelitian (Samiasih \& Hartiti, 2013) menyatakan bahwa bekam basah trigliserida normal dalam darah adalah $<150 \mathrm{mg} / \mathrm{dL}$. Kriteria garis batas tinggi jika kadarnya 150 - 199 mg/dL, kriteria menurunkan kadar kolesterol, trigliserida dan asam urat pada pasien migren di Demak.

tinggi jika kadarnya 200 - $499 \mathrm{mg} / \mathrm{dL}$ dan

Bekam salah satu metode kriteria sangat tinggi jika kadarnya >500mg/dL (Munawwarah, 2011).

Kadar trigliserida yang tinggi dapat memicu beberapa penyakit, di antaranya yaitu dapat menyebabkan penyempitan dan pengerasan di dalam pembuluh darah arteri akibat pengendapan kolesterol dan zat-zat lemak (aterosklerosis), timbul pengobatan komplementer yang dilakukan dengan menggunakan vacum cups. Adapun mekanisme yang mendasari efek terapi bekam basah terhadap penurunan kadar trigliserda darah, terbukanya barier kulit yang akan meningkatkan fungsi ekskresi kulit diantaranya mengeluarkan lipid dan substansi atau material yang 
bersifat hidrofobik. Terapi bekam basah dapat mengekskresikan material hidrofilik dan hidrofobik salah satu contohnya adalah lipoprotein (Widodo \& Khoiriyah, 2014).

Melihat Permasalahan diatas, maka peneliti tertarik untuk melakukan penelitian mengenai perbedaan kadar trigliserida wanita sebelum dan sesudah terapi bekam. Hasil penelitian ini dapat menjadi dasar penelitian lebih lanjut untuk mendapatkan pengetahuan yang lebih luas dalam rangka menyusun perencanaan dan program terapi bekam.

Tujuan umum penelitian ini untuk mengetahui perbedaan kadar trigliserida wanita sebelum dan sesudah terapi bekam di Pondok Pengobatan Alternatif Miftahussyifa Kota Bengkulu dan tujuan khusus penelitian ini untuk mengetahui distribusi frekuensi kadar trigliserida wanita sebelum dan sesudah terapi bekam di Pondok Pengobatan Alternatif Miftahusyifa Kota Bengkulu, untuk mengetahui rerata kadar trigliserida wanita sebelum dan sesudah terapi bekam di Pondok Pengobatan Alternatif Miftahussyifa Kota Bengkulu, dan untuk mengetahui perbedaan kadar trigliserida pada wanita yang melakukan terapi bekam di Pondok Pengobatan Alternatif Miftahussyifa Kota Bengkulu.

\section{BAHAN DAN CARA KERJA}

Jenis penelitian yang dilakukan bersifat Analitik. Desain penelitian yang digunakan adalah Rancangan penelitian pre-eksperimen dengan one group prepost test design. Sampel penelitian ini diambil dengan metode purposive sampling yang terdiri dari 32 responden yang telah memenuhi kriteria inklusi dan eksklusi sampel. Sebelum saya mengambil sampel darah vena ke responden saya meminta persetujuan secara tertulis (inform concern) terlebih dahulu.

Data yang telah didapat dari hasil penelitian selanjutnya diolah secara statistik dengan menggunakan Uji $\mathrm{T}$ dependen. Data diolah dengan menggunakan Uji Shapiro-Wilk untuk melihat normalitas data, jika data berdistribusi normal maka dipilih Uji $\mathrm{T}$ dependen, namun jika data tidak berdistribusi normal dilakukan transformasi data terlebih dahulu. Jika variabel baru hasil transformasi berdistribusi normal, maka digunakan Uji $\mathrm{T}$ dependen. Jika variabel baru hasil transformasi tidak berdistribusi normal, maka dipilih Uji Wilcoxon. Pada penelitian ini digunakan Uji Shapiro-Wilk untuk melihat normalitas data dan hasil yang didapat yaitu data berdistribusi 
normal sehingga dapat langsung $\mathrm{mg} / \mathrm{dL}$ dan nilai rerata kadar trigliserida dilanjutkan dengan Uji $\mathrm{T}$ dependen untuk melihat ada tidaknya perbedaan kadar trigliserida wanita sebelum dan sesudah terapi bekam.

\section{HASIL}

Tabel 1 diketahui hampir sebagian responden memiliki kadar trigliserida normal sebelum terapi bekam $(28,13 \%)$, sebagian besar responden memiliki kadar trigliserida abnormal (tinggi) sebelum terapi bekam $(71,87 \%)$, sebagian kecil responden memiliki kadar trigliserida normal sesudah terapi bekam (25\%), dan sebagian besar responden memiliki kadar trigliserida abnormal (tinggi) sesudah terapi bekam $(75 \%)$.

Tabel 1 Distribusi Frekuensi Kadar Trigliserida Sebelum dan Sesudah Terapi Bekam

\begin{tabular}{lcc}
\hline $\begin{array}{l}\text { Kadar trigliserida } \\
\text { sebelum terapi } \\
\text { bekam }\end{array}$ & Frekuensi & Persentasi \\
\hline $\begin{array}{l}\text { Normal } \\
\begin{array}{l}\text { Abnormal } \\
\text { (tinggi) }\end{array}\end{array}$ & 23 & 28,13 \\
\hline Total & 32 & 100 \\
\hline $\begin{array}{l}\text { Kadar trigliserida } \\
\text { sesudah terapi } \\
\text { bekam }\end{array}$ & Frekuensi & Persentasi \\
\hline $\begin{array}{l}\text { Normal } \\
\begin{array}{l}\text { Abnormal } \\
\text { (tinggi) }\end{array}\end{array}$ & 8 & \\
\hline Total & 24 & 25 \\
\hline
\end{tabular}

Tabel 2 menunjukkan hasil analisis rerata kadar trigliserida sebelum dan sesudah terapi bekam mengalami penurunan dengan nilai rerata kadar trigliserida sebelum terapi bekam 208,28 sesudah terapi bekam $200,59 \mathrm{mg} / \mathrm{dL}$.

Tabel 2 Hasil Analisis Rerata Kadar Trigliserida Sebelum dan Sesudah Terapi Bekam

\begin{tabular}{|c|c|c|c|c|c|}
\hline Variabel & $\mathrm{n}$ & Mean & $\begin{array}{c}\text { Media } \\
n\end{array}$ & Min & Max \\
\hline $\begin{array}{l}\text { Kadar } \\
\text { trigliserida } \\
\text { sebelum } \\
\text { terapi } \\
\text { bekam }\end{array}$ & 32 & $\begin{array}{c}208,2 \\
8\end{array}$ & $\begin{array}{c}200,0 \\
0\end{array}$ & 106 & 370 \\
\hline $\begin{array}{l}\text { Kadar } \\
\text { trigliserida } \\
\text { sesudah } \\
\text { terapi } \\
\text { bekam } \\
\end{array}$ & 32 & $\begin{array}{c}200,5 \\
9\end{array}$ & $\begin{array}{c}188,0 \\
0\end{array}$ & 118 & 347 \\
\hline
\end{tabular}

Tabel 3 diketahui hasil analisis Uji $\mathrm{T}$ dependen dengan nilai $p=0,002(\mathrm{p}<$ 0,05) maka dapat diambil kesimpulan ada perbedaan yang signifikan terhadap kadar trigliserida sebelum dan sesudah terapi bekam.

Tabel 3 Hasil Analisis Uji T Dependen Kadar Trigliserida Sebelum dan Sesudah Terapi Bekam

\begin{tabular}{|c|c|c|c|c|}
\hline Variabel & $\mathrm{N}$ & $\begin{array}{c}\text { Mean } \pm \\
\text { SD }\end{array}$ & IK 95\% & $P$ \\
\hline $\begin{array}{l}\text { Sebelum } \\
\text { terapi } \\
\text { bekam }\end{array}$ & 32 & $\begin{array}{l}208,28 \pm \\
71,319\end{array}$ & $\begin{array}{l}3,105- \\
12,270\end{array}$ & 0,002 \\
\hline $\begin{array}{l}\text { Sesudah } \\
\text { terapi } \\
\text { bekam }\end{array}$ & 32 & $\begin{array}{l}200,59 \pm \\
68,898\end{array}$ & & \\
\hline
\end{tabular}

Hasil penelitian menunjukkan adanya penurunan kadar trigliserida setelah terapi bekam. Jumlah keseluruhan pasien pada penelitian ini 32 orang, diketahui sebanyak 27 orang $(84,375 \%)$ mengalami penurunan kadar trigliserida sesudah terapi bekam dan sebanyak 5 orang $(15,625 \%)$ mengalami peningkatan kadar trigliserida sesudah terapi bekam. 


\section{PEMBAHASAN}

Proses penurunan kadar trigliserida terjadi dimana tekanan negatif (kekuatan hisap) diterapkan di permukaan kulit menggunakan cup yang membuat kulit terhisap kedalamnya. Karena tekanan negatif ini membuat laju filtrasi kapiler menuju daerah cupping menjadi cepat dan menurunkan absorbsi di kapiler vena yang meninggalkan daerah cupping. Peningkatan filtrasi kapiler-kapiler kulit ini akan mengakibatkan banyaknya cairan dan zat-zat berbahaya yang terfiltrasi menumpuk di daerah cupping. Selain itu, tekanan negatif ini juga akan mengumpulkan cairan limfe dan interstisial di daerah cupping. Subtansi kimia, mediator inflamasi, dan mediator nyeri yang mencair ini akan menggenangi ujung-ujung saraf sensoris di daerah cupping dan memutus adhesi jaringan yang akan menurunkan rasa nyeri (Wicaksono \& Larasati, 2016).

Penusukan pada daerah cupping akan membuka barrier kulit untuk mengeluarkan cairan bersama zat-zat berbahaya dan mencegah absorbsinya di ujung kapiler vena. Penusukan ini pada akhirnya akan menghasilkan peningkatkan pembersihan plasma darah dari materialmaterial penyebab penyakit, seperti radikal bebas, kolesterol, dan zat-zat berbahaya lainnya. Setelah penusukan tekanan negatif menggunakan cupping kembali dilakukan pada daerah tersebut. Tekanan negatif yang kedua kalinya ini menyebabkan seluruh cairan yang terkumpul (bersama zat-zat berbahaya) keluar hingga seluruh cairan yang terkumpul pada area cupping habis. Karena ada gradien tekanan yang sangat besar pada penambahan cupping kedua ini pada ujung kapiler arteriol dan venula akan menyebabkan filtrasi pada kedua ujung kapiler tersebut. Hal ini menyebabkan peningkatan pembersihan plasma darah. Pembersihan zat-zat berbahaya ini akan menimbulkan luka pada jaringan tersebut. Dengan adanya hemostasis dari tubuh maka luka tersebut akan mengalami proses pemulihan secara fisiologis. Cairan interstisial yang baru akan datang melalui filtrasi pada arteriol kapiler kulit setelah pembersihan cairan yang berisi zat-zat berbahaya sebelumnya. Hemostasis fisiologi ini merupakan perbaikan baru setelah terapi bekam basah (Wicaksono \& Larasati, 2016).Selama penelitian dilaksanakan terdapat beberapa keterbatasan yang peneliti alami diantaranya ada 5 orang responden yang tidak bersedia diambil sampel darah vena sebanyak dua kali yaitu sebelum terapi bekam dan sesudah terapi bekam 
dikarenakan responden mengalami trauma dan ketakutan saat pengambilan sampel darah vena pertama yang menyebabkan responden tidak bersedia untuk diambil sampel darah vena kedua pada hari yang sama, sehingga pengambilan sampel darah vena responden yang kedua dilakukan 1 hari setelah pembekaman. Hal ini mengakibatkan adanya peningkatan kadar trigliserida sesudah terapi bekam. Ada perbedaan antara kolesterol total sebelum dan sesudah terapi bekam dengan pengambilan darah vena pertama dilakukan sebelum pembekaman kemudian pengambilan darah vena kedua dilakukan 1 hari setelah pembekaman pada sampel yang sama. Penurunan kadar kolesterol total pada pasien terapi bekam diakibatkan pengeluaran plak-plak kolesterol berlebih yang menumpuk pada pembuluh darah serta perangsangan proses lipolisis jaringan lemak saat pembekaman. Pengekopan (penghisapan) pada kulit yang dibekam menimbulkan tekanan negatif sehingga membantu proses pengeluaran plak-plak kolesterol tersebut.Bekam merupakan suatu metode

\section{DAFTAR RUJUKAN}

Munawwarah, M. (2011). Penambahan Pelatihan Kekuatan Otot Pada Pelatihan Interval Menurunkan Trigliserida Mahasiswi Gemuk. Jurnal Fisioterapi, 11(1).

Oway, I. A. H., Kalangi, S. J. . R., \& Pasiak, T. (2013). Perbandingan kadar trigliserida pada obes 1 dan obes 2. Jurnal E-Biomedik pengobatan yang dilakukan dengan cara mengeluarkan darah yang sudah tua melalui pembuluh-pembuluh kapiler. Bekam diawali dengan pembendungan lokal pada daerah kulit yang ingin dibekam. Pembendungan lokal tersebut sebagai hasil dari tekanan negatif oleh pengekopan dengan menggunakan tabung atau gelas(Rahmanda et al., 2016).

\section{KESIMPULAN}

Ada perbedaan kadar trigliserida yang signifikan sebelum dan sesudah terapi bekam di Pondok Pengobatan Alternatif Miftahussyifa Kota Bengkulu. Terapi bekam memberikan dampak yang baik bagi kesehatan, salah satunya terapi bekam dapat menurunkan kadar trigliserida yang tinggi dimana peningkatan kadar trigliseridadapat memicu beberapa penyakit, di antaranya dapat menyebabkan penyempitan dan pengerasan di dalam pembuluh darah arteri akibat pengendapan kolesterol dan zat-zat lemak (aterosklerosis), timbul gejala penyakit diabetes komplikasi dan sindrom metabolik.

\section{(eBM), 1, 357-363.}

Patonah, Yuniarto, A., \& Nurhandayati, C. (2014). Aktivitas antihipertrigliseridemia ekstrak kunyit (Curcuma longa L)Dan bangle (Zingiber cassumunar Roxb) Serta

kombinasinya pada hewan hipertrigliseridemia. Jurnal Farmasi Galenika, 1(2), 54-60.

Samiasih, A., \& Hartiti, T. (2013). Gambaran 
Kadar Trigliserid Akseptor KB Suntik DMPA Yang Dilakukan Bekam Basah.

Wicaksono, T. D., \& Larasati, T. A. (2016). Mekanisme Bekam sebagai Terapi Alternatif dalam Menurunkan Hipertensi Mechanism of Wet Cuppingas Alternative Therapy in Lowering Hypertension. Majority, 5(April), 112-119.

Widodo, S., \& Khoiriyah. (2014). Efek Terapi Bekam Basah Terhadap Kadar Kolesterol Total Pada Penderita Hiperkolesterolmia Di Klinik Bekam Center Semarang. Prosiding Seminar Nasional.
Wowor, F. J., Ticoalu, S. H. R., \& Wongkar, D. (2013). Perbandingan Kadar Trigliserida Darah Pada Pria Perokok dan Bukan Perokok. Jurnal E-Biomedik, 1(2), 986-990.

Rahmanda, Y., Seto, R., \& Sugiarti, M. (2016). Gambaran Kadar Kolesterol Total pada Pasien Terapi Bekam di tempat Pelayanan Kesehatan Tradisional Bekam Herbal Center ( BHC ) Kedaton Kota Bandar Lampung Overview Total Cholesterol Levels in Patients Cupping Therapy in Place Cupping Traditional Herbal He. Jurnal Analis Kesehatan, 5(1). 